\title{
To Internationalize Rapidly from Inception: Crowdsource
}

\author{
Elnaz Heidari, Mohsen Akhavannia, and Nirosh Kannangara
}

\author{
"Why wouldn't you want to make the products that" \\ people want you to make? \\ Jake Nickell \\ Founder and $\mathrm{COO}$ of Threadless
}

\begin{abstract}
Technology entrepreneurs continuously search for tools to accelerate the internationalization of their startups. For the purpose of internationalizing rapidly from inception, we propose that technology startups use crowdsourcing to internalize the tacit knowledge embodied in members of a crowd distributed across various geographies. For example, a technology startup can outsource to a large crowd the definition of a customer problem that occurs across various geographies, the development of the best solution to the problem, and the identification of attractive business expansion opportunities.
\end{abstract}

In this article, we analyze how three small firms use crowdsourcing, discuss the benefits of crowdsourcing, and offer six recommendations to technology entrepreneurs interested in using crowdsourcing to rapidly internationalize their startups from inception.

\section{Introduction}

How can a technology startup internationalize rapidly from inception when it has scarce resources and limited knowledge about the needs of customers in various geographies? In this article, we argue that crowdsourcing is a low-cost process that can help a startup internationalize rapidly from inception.

Crowdsourcing is "the act of a company or institution taking a function once performed by employees and outsourcing it to an undefined, and generally large, network of people in the form of an open call" (Howe, 2008; tinyurl.com/9tz42kj). The core of the concept is to access the collective intelligence of a distributed group of people to complete business-related tasks that a company would normally perform itself or would be outsourced to a third party. Crowdsourcing can be used to collect information, solve problems, clean up data, classify content, select options, create new content, and complete many other tasks.
Figure 1 illustrates a crowdsourcing process. Interactions between the startup and a group of people, or "the crowd", anchor the process. The startup makes an open call to a crowd by providing information about the tasks that are outsourced to the crowd. Individuals respond with offers of what they can provide the startup. The startup or its agent then selects a subset of the crowd to carry out the tasks. If the crowd successfully completes the tasks, they may be asked to complete other tasks.

This article contributes suggestions on how entrepreneurs can use the process shown in Figure 1 to rapidly internationalize their startups. The next section provides the results of our analysis of the crowdsourcing processes used by three startups, Threadless, 360Cities, and 99designs and then identifies the main benefits to startups of crowdsourcing. Next, we suggest what a technology startup should do to accelerate its internationalization from inception. Finally, we provide concluding remarks and offer suggestions for future research. 


\section{To Internationalize Rapidly from Inception: Crowdsource}

\section{Elnaz Heidari, Mohsen Akhavannia, and Nirosh Kannangara}

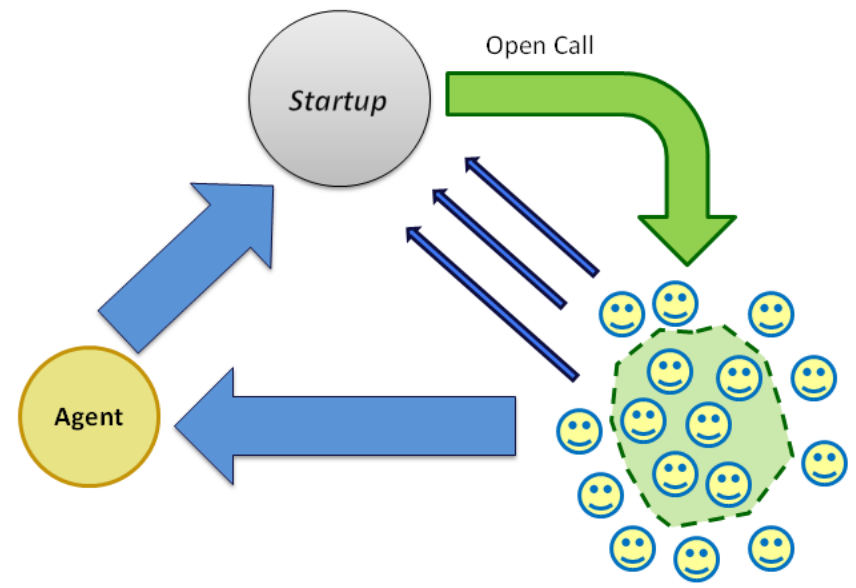

Figure 1. The crowdsourcing process*

*Adapted from Schenek and Guittard (2009; tinyurl.com/9ztusro)

\section{Crowdsourcing Processes}

We decided to examine the crowdsourcing processes that are essential to the success of startups that internationalized rapidly. In this section, we first identify three startups that could not have internationalized rapidly without crowdsourcing and then compare their crowdsourcing processes.

\section{Cities}

360Cities (360cities.net) enables the publishing of highquality panoramic photography. Its platform automates the process of publishing panoramas, processing them for tiled multi-resolution display, locating them on a world map, and embedding them into websites. 360Cities was founded with angel funding in Prague, Czech Republic, in 2007. The company started with six employees. The 360Cities crowdsourcing process accesses millions of panoramic photographs from places around the globe each year. Crowds of photographers provided the materials for 360Cities to dominate the panoramic photograph market in less than three years from inception.

\section{9 designs}

99designs (99designs.com) operates an online marketplace for crowdsourced graphic design. According to the company, a new design is uploaded every five seconds and more than $\$ 40$ million has been paid out to its design community since 2008 . The company started with three employees in Melbourne, Australia, in 2008. 99designs uses crowdsourcing to enable small companies to find design experts at affordable prices. A crowd comprised of thousands of designers compete to satisfy clients who need logos, websites, business cards, or other design-related tasks required to operate their small businesses. In 2012, the company hired employees located in San Francisco, Melbourne, Berlin, and London.

\section{Threadless}

Threadless (threadless.com) is a T-shirt company that was founded in Chicago, USA, in 2000. Threadless relies on an online community of artists that contribute novel ideas to customize the firm's T-shirt products. Threadless enables potential customers to produce the designs of the T-shirts that they intend to buy. In 2004, the firm's revenue was around $\$ 1.5$ million, and in 2006 it jumped to $\$ 6.5$ million.

Table 1 compares the crowdsourcing processes used by these three companies in terms of the tasks that are routinely assigned to the crowds, who are dominant in the crowds, what motivates crowds to participate, how crowds participate, and the main costs incurred by the startups.

\section{Benefits of Crowdsourcing}

Crowdsourcing offers startups at least five important benefits. First, it decreases marketing and sales costs. For example, Threadless collects designs from the crowd and sells T-shirts to that same crowd. Thus, the company sells T-shirts with no advertising costs, no professional designers, no sales force, and no retail distribution (Chafkin, 2008; tinyurl.com/5mddgj). When Accel Partners invested \$35 million in 99designs, Patrick Llewellyn, the company's CEO was quoted as saying: “More than $90 \%$ of 99designs' customers come through word of mouth. Imagine if the company actually invested in sales and marketing." (Lacy, 2011; tinyurl.com/ 9nr98j6). Thus, the use of crowdsourcing reduces marketing and sales costs.

The second benefit that crowdsourcing provides a startup is increased public awareness about the firm's existence and a higher volume of interactions. A startup that makes an open call to a crowd becomes better known in the online community (Walter and Back, 2010; tinyurl.com/8d7umxl). The part of the crowd that responds to the call and completes the tasks becomes aware of what the firm does and why it does it.

The third benefit that crowdsourcing provides a startup is deeper insights about customers and channel partners in different geographies. 


\section{To Internationalize Rapidly from Inception: Crowdsource}

\section{Elnaz Heidari, Mohsen Akhavannia, and Nirosh Kannangara}

Table 1. A comparison of the crowdsourcing processes used by three small firms

\begin{tabular}{|c|c|c|c|}
\hline & Threadless & 360Cities & 99designs \\
\hline $\begin{array}{l}\text { What } \\
\text { (Tasks assigned } \\
\text { to crowds) }\end{array}$ & $\begin{array}{l}\text { - Create new designs } \\
\text { - Vote on best designs } \\
\text { - Improve existing designs }\end{array}$ & $\begin{array}{l}\text { - Provide panoramic photographs of } \\
\text { worldwide locations }\end{array}$ & $\begin{array}{l}\text { - Provide graphic designs based on } \\
\text { client needs } \\
\text { - Provide design estimates }\end{array}$ \\
\hline $\begin{array}{l}\text { Who } \\
\text { (Who are the } \\
\text { crowds) }\end{array}$ & $\begin{array}{l}\text { - Artists and graphic designers } \\
\text { - General public }\end{array}$ & $\begin{array}{l}\text { - Professional photographers from } \\
\text { global communities }\end{array}$ & $\begin{array}{l}\text { - Artists and graphic designers } \\
\text { - Web and mobile application } \\
\text { designers } \\
\text { - Advertisement designers }\end{array}$ \\
\hline $\begin{array}{l}\text { Why } \\
\text { (Motivation for } \\
\text { crowds) }\end{array}$ & $\begin{array}{l}\text { - Cash and Threadless credits } \\
\text { - Designers names are printed on T- } \\
\text { shirts } \\
\text { - Designs are copyrighted } \\
\text { - Increase in knowledge about } \\
\text { designs }\end{array}$ & $\begin{array}{l}\text { - Provide advice and information to } \\
\text { photographers on a wide range of } \\
\text { technical, artistic, and commercial } \\
\text { topics } \\
\text { - Photographers names are on the } \\
\text { photos } \\
\text { - Photographers maintain } 360 \text { Cities } \\
\text { portfolio pages } \\
\text { - Promote business through } \\
\text { 360Cities }\end{array}$ & $\begin{array}{l}\text { - Build up customer relationships } \\
\text { through 99designs website } \\
\text { - Build portfolio and recognition } \\
\text { through 99designs } \\
\text { - Earn money when the graphic } \\
\text { design is selected } \\
\text { - Designs are copyrighted }\end{array}$ \\
\hline $\begin{array}{l}\text { How } \\
\text { (Tools and } \\
\text { processes } \\
\text { employed) }\end{array}$ & $\begin{array}{l}\text { - Software platform and website to } \\
\text { submit new designs } \\
\text { - Voting system to confirm and } \\
\text { accept good designs } \\
\text { - Forums to share ideas }\end{array}$ & $\begin{array}{l}\text { - Photo stitching tools for the crowd } \\
\text { to create panoramic photos } \\
\text { - Forums to share ideas, discussions, } \\
\text { and professional advice } \\
\text { - Website to share photographs } \\
\text { submitted by photographers }\end{array}$ & $\begin{array}{l}\text { - Web platform to submit designs } \\
\text { - Designer and client forums to } \\
\text { share ideas } \\
\text { - Tool for clients to submit their } \\
\text { design briefs and expectations }\end{array}$ \\
\hline Costs & $\begin{array}{l}\text { - Four ambassadors who engage in } \\
\text { the online community } \\
\text { - Operation of website and online } \\
\text { tools to submit and process } \\
\text { designs } \\
\text { - In person and online community } \\
\text { events }\end{array}$ & $\begin{array}{l}\text { - Supporting a database of } \\
\text { photographs submitted by } \\
\text { photographers } \\
\text { - Contests and incentives to the } \\
\text { crowd } \\
\text { - Paying photographers }\end{array}$ & $\begin{array}{l}\text { - Operating designer and client } \\
\text { forums } \\
\text { - Staff to handle crowd-related } \\
\text { issues }\end{array}$ \\
\hline
\end{tabular}

The fourth benefit of crowdsourcing is that it enables the startup to leverage expensive resources (i.e., the time of the individuals who participate in the crowd) with a relatively small initial investment. For example, the two Threadless co-founders invested $\$ 1,000$ of their own money to launch and grow their startup, and now, the crowd invests its time in creating and submitting 1000 new designs to the website each week.

The fifth benefit is that crowdsourcing allows the startup to attract large partners and customers. When crowdsourcing attracts a significant number of users, large, well-established vendors, partners, and customers become interested in the startup. For example, Google became interested in 360cities because it engaged a large crowd of photographers; this crowd was of interest to Google because of their Google Earth program. Microsoft (Bing) and Nokia also became interested in the mapping-related capabilities of the startup after its partnership with Google Earth was announced (tinyurl.com/ 6k93qgm). Similarly, large companies such as Dell and Apple are selling Threadless laptops, laptop sleeves, and switch lids, and Griffin and Apple are selling iPhone cases with Threadless designs (tinyurl.com/97ojjqt). 


\title{
To Internationalize Rapidly from Inception: Crowdsource
}

\author{
Elnaz Heidari, Mohsen Akhavannia, and Nirosh Kannangara
}

\section{Crowdsourcing to Internationalize Rapidly}

In this section, we use what we learned from examining how three startups, 360Cities, 99designs, and Threadless, used crowdsourcing to provide suggestions for entrepreneurs who wish to establish crowdsourcing environments to accelerate the internationalization of their startups from inception.

\section{Attract the appropriate crowd}

Crowdsourcing requires a "good crowd", particularly in terms of the quality of contributors. Proper crowd selection and management can help startups internationalize rapidly from inception. We make the following suggestions:

- Attract into the crowd the individuals who care the most about solving the problem described by the startup's open call. For example, the open call from 360Cities attracted photographers who were eager to experience an interesting photography technique.

- Attract crowds from different geographies. A crowd should include individuals from different places around the world. This will increase global acceptance of the company's offer and accelerate innovation.

- Attract a crowd that can help sell the startups' products. Convert the crowd into customers and an international sales force. An interesting feature of crowdsourcing is that it attracts both potential suppliers, buyers, and channel partners.

\section{Reduce the cost of screening ideas}

Attracting a large international crowd can result in a high cost of screening ideas. The startup should focus on quality, not quantity. Too many ideas will be burdensome and costly since every idea submitted needs to be examined. 99designs automates the process clients use to screen the designs they need. However, in the case of Threadless, employees manage the crowdsourcing process and screen the designs.

\section{Modularize the tasks that are outsourced to the crowd}

Tasks outsourced to global crowds need to be modular and finite. Taking photos and designing T-shirts are examples of modular finite tasks. Do not expect a crowd that is distributed globally to integrate complex tasks.

\section{Motivate the international crowd}

Startups need to understand what motivates talented submitters to participate in crowdsourcing (Trompette et al., 2008; tinyurl.com/8q3uvs7). They must define what motivates submitters in the international crowd and provide compelling incentives based on the crowds' expectations of contributions. Members of a crowd are motivated by different things. Therefore, to satisfy an international crowd, the startup should offer various incentives, not just one. For example, 360cities photographers can receive a share of the profits generated when their photographs are licensed to third parties, have their names printed in their photographs, and so on.

\section{Align tools and processes with outcomes}

Tools and processes play a key role in crowdsourcing. In the case of 360cities, their weblogs enable members of the crowd to communicate, and the automatic photo stitcher facilitates panoramic photo conversion. Similarly, Threadless and 99Designs provide design environments to help designers in crowds to realize their ideas. These two companies also provide appropriate tools for voters to judge the submitted designs.

Tools and processes need to be simple and easy to use by individuals located in various geographies and with different cultures and languages. If members of the crowd have difficulties learning about the crowdsourcing environment, their productivity will decrease.

\section{Develop a plan to prevent and handle capacity over- loads}

Startups must develop a plan to prevent capacity overloads as well as deal with any overloads that do occur. For example, 360cities moved its systems to Amazon after being overloaded by photo uploads on its automatic photo stitcher.

\section{Conclusion}

This article describes how a startup firm can use crowdsourcing to internationalize rapidly from inception. It shows how firms can use crowdsourcing to gather global ideas and solutions to address the latent needs of foreign customers. By recognizing global-customer needs using different global crowds, crowdsourcing provides firms with the opportunity to customize their products and services to suit the different demands in foreign markets

This article also provides evidence of recent companies that were successful using crowdsourcing as their main business pattern. Through these case studies, the article elaborates on the different methods the firms used to effectively attract crowds and exploit the power of the crowd in their path to rapid international growth. 


\section{To Internationalize Rapidly from Inception: Crowdsource}

\section{Elnaz Heidari, Mohsen Akhavannia, and Nirosh Kannangara}

However, not all businesses are as highly dependent on crowds as the case studies in this article. Therefore, more research is required to answer questions such as when and how to democratize creativity in different firms with variety of business structure, and how crowdsourcing impacts progress with rapid internationalization. Also, there is little information on how technology startups can align crowdsourcing outcomes with technology growth to stay competitive in an international market.

This article highlights the potential that crowdsourcing holds in facilitating a rapid internationalization process. The main challenges entrepreneurs face when crowdsourcing are choosing an appropriate crowd to collect ideas from and then filtering the quality ideas that come from that crowd.

\section{About the Authors}

Elnaz Heidari holds a Master of Engineering degree in Technology Innovation Management (TIM) from Carleton University in Ottawa, Canada. Her M.Eng project was based on crowdsourcing and open innovation. She also holds a B.Eng in Rubber Industrial Engineering. Her industrial experience includes working in the R\&D department of Pars Vacuum Industries for two years.

Mohsen Akhavannia is a graduate student in the Technology Innovation Management (TIM) program at Carleton University in Ottawa, Canada. He is a software engineer with expertise in system analysis and design. He has six years of international work experience including work on projects relating to banking and business-automation systems.

Nirosh Kannangara is a graduate student in the Technology Innovation Management (TIM) program at Carleton University in Ottawa, Canada. He holds a B.Eng. in Communications Engineering, also from Carleton University. Nirosh has two years of experience designing software in the fibre optics communication industry and currently works as a Photonics Software Designer at the Ciena Corporation.

Citation: Heidari, E., M. Akhavannia, and N.

Kannangara. 2012. To Internationalize Rapidly from

Inception: Crowdsource. Technology Innovation

Management Review. October 2012: 17-21. (cc) BY 